\title{
The Moses Mabhida Medical Plan: medical care planning and execution at a FIFA20 I 0 stadium; the Durban experience
}

This article was published in the following Dove Press journal:

Open Access Emergency Medicine

6 December 2010

Number of times this article has been viewed

\author{
Timothy C Hardcastle ${ }^{1,2}$ \\ Mergan Naidoo ${ }^{3,4}$ \\ Sanjay Samlal ${ }^{5,6}$ \\ Morgambery Naidoo $0^{5,6}$ \\ Timothy Larsen ${ }^{5,6}$ \\ Muzi Mabasu ${ }^{5,6,7}$ \\ Sibongiseni Ngema ${ }^{6,8}$ \\ 'Inkosi Albert Luthuli Hospital, \\ Mayville, South Africa; ${ }^{2}$ Department of \\ Surgery, University of KwaZulu-Natal, \\ Durban, South Africa; ${ }^{3}$ Wentworth \\ Hospital, Durban, South Africa; \\ ${ }^{4}$ Department of Family Medicine, \\ University of KwaZulu-Natal, Durban, \\ South Africa; ${ }^{5}$ Emergency Medical \\ Rescue Service, KwaZulu-Natal, \\ South Africa; ${ }^{6}$ Department of Health, \\ KwaZulu-Natal, South Africa; ${ }^{7}$ EMRS \\ 2010 Planning Committee, \\ KwaZulu-Natal, South Africa; \\ ${ }^{8} \mathrm{School}$ of Public Administration and \\ Development Management, \\ University of KwaZulu-Natal, \\ Durban, South Africa
}

Correspondence: Timothy C Hardcastle Inkosi Albert Luthuli Hospital, Private Bag X03, Mayville 4058, South Africa $\mathrm{Tel}+27824681615$

Fax +27865215177

Email timothyhar@ialch.co.za.
Aim: This paper aims to outline the medical services provided at the Moses Mabhida Stadium, Durban, South Africa for the Fédération Internationale de Football Association (FIFA) 2010 Soccer World Cup and audit the clinical services delivered to persons seeking medical assistance.

Methods: Descriptive report of the medical facilities at the Moses Mabhida Stadium including the staff deployment. Retrospective data review of medical incident reports from the Stadium Medical Team.

Results: Medical staffing exceeded the local norms and was satisfactory to provide rapid intervention for all incoming patients. Senior medical presence decreased the transport to hospital rate (TTHR). A total of 316 spectators or support staff were treated during the seven matches played at the stadium. The majority of patients were male $(60 \%)$, mostly of local origin, with mostly minor complaints that were treated and discharged (88.2\% Green codes). The most common complaints were headache, abdominal disorders, and soft-tissue injuries. One fatality was recorded. The patient presentation rate (PPR) was $0.66 / 10,000$ and the TTHR was overall $4.1 \%$ of all treated patients $(0.027 / 10,000$ spectators $)$.

Conclusion: There was little evidence to guide medical planning for staffing from the FIFA governing body. Most patients are treated and released in accordance with international literature, leading to low TTHR rates, while PPR was in line with international experience. Headache was the most common medical complaint. The blowing of Vuvuzelas ${ }^{\circledR}$ may have influenced the high headache rate.

Keywords: spectator, soccer, world cup, emergency, Vuvuzela

\section{Introduction}

Southern Africa has previously hosted numerous mass gathering events, including the visit of the Pope to Lesotho in $1988^{1}$ and major sports events such as the Rugby (1995) and Cricket (2003) World Cup tournaments; however, none of these were of the scale of the Fédération Internationale de Football Association (FIFA) Soccer World Cup $2010^{\mathrm{TM}}$. The planning process was initiated in 2007 at the insistence of the Department of Health. ${ }^{2,3}$

Planning for the Soccer World Cup was subject to the guarantee from the South African Government to FIFA for the provision of emergency and other medical services to the teams, officials, and delegates from all of the participating nations, from within the Department of Health.

In an attempt to provide some early guidance to the health care providers in South Africa, a component overview was undertaken by the Department of Health 
in cooperation with researchers from Emory University in Atlanta, Georgia, USA, which highlighted the need for comprehensive public health and emergency care planning, both in the layout of the physical resources, at the stadium as well as in the hospital, and the preparation of staff for potential mass casualty events. ${ }^{4}$

Milsten and coworkers highlighted the lack of uniform guidelines and standards in the literature, especially as some reports include the management of disasters in the same context as mass gathering medicine. ${ }^{5}$ They also emphasize the need to integrate the planning within the existing emergency medical care system, given that routine emergency care must continue. These recommendations were applied to the Durban stadium plan.

Arbon points out that "mass gatherings are characterized by large crowds of spectators and participants" and yet, that there are higher patient contact episodes compared with the general population, despite being a collection of generally "well persons". ${ }^{6}$ The data presented here attempt to follow the standards and definitions that are in force, while highlighting the aspects particular to soccer spectator care.,

This report reviews the planning process for this brand new stadium, the stadium medical resources provided, and the patient profile of cases managed at the stadium during the FIFA matches at Durban's new Moses Mabhida Stadium. Additionally this report mentions the role of a predetermined mass-casualty care area that was required by FIFA, for which there was no high-quality evidence on which to base the staff and equipment allocation.

\section{Stadium}

The Moses Mabhida Stadium is one of the completely new stadiums built specifically for the Soccer World Cup, with a seating capacity of over 63,000 people, excluding staff and vendors. The total capacity is nearer 70,000. Access and egress routes were planned to allow for a complete evacuation of the stadium within around 12-15 minutes. Durban's new Moses Mabhida Stadium hosted five games in the group phase, one of the "round of 16" matches, and one of the semifinal encounters. At FIFA's insistence, the stadium's access and egress were on foot from outside an exclusion zone of approximately $2 \mathrm{~km}$, for security reasons.

The medical facilities within the stadium comprise the following: a six-bedded spectator medical center with full resuscitation capability, including an isolation room; a small medical room for minor cases on the opposite side of the stadium; two players' medical centers, and a doping control room. Additionally there are medical standby points at all four corners of the stadium on each level and a medical holding area in the VIP center. Parking for four ambulances was provided (see Figure 1).

For the duration of the FIFA 2010 World Cup, the Emergency Medical Rescue Services (EMRS), KwaZulu-Natal, provided two golf-cart medical vehicles for evacuation within the stadium to the medical treatment facilities.

Command and control was exercised from the Stadium Venue Operations Center, reporting to the Host City and Provincial Joint Operations Canters for external backup. Within the stadium, the overall command was held by the South African Police Service (Major General Bala Naidoo), with control of each service devolved to the individual service commanders. Management team meetings were held every 2 hours during match days to identify problems and share concerns.

\section{Staffing estimation}

The Emergency Medicine Society of South Africa (EMSSA) has a document ${ }^{8}$ for staff and equipment estimation based on the national policy document for events management (SANS 10366), ${ }^{9}$ which was utilized to estimate the ideal staffing requirements and level of care provision for stadiums involved in the World Cup event. This national standards document was issued by South African Bureau of Standards on behalf of the National Department of Health and the FIFA Local Organizing Committee, through a health technical task team as the national standard for mass gatherings.

Based on the EMSSA document, ${ }^{8}$ the minimum staffing requirements were determined as follows: two doctors, one Intensive Care Unit (ICU)-Trauma Nurse, three advanced life support paramedics (ALS), three intermediate life support paramedics (ILS), and 24 basic life support paramedics (BLS), plus full crew for the minimum of three ambulances (equipped to ILS level). With the planning process, the requirements were exceeded with ease. All practitioners were to practice according to the Health Professions Council of South Africa Scope of Practice for their discipline.

The eventual daily deployment included, on average, five ALS, 10 ILS, 20 BLS, and the required number of doctors and nurses, with additional cover provided by the five Local Organizing Committee doctors (two on the field, two in the players' medical rooms, and one in the VIP suite), the FIFA doping control officials and the Local Organizing Committee Medical Officer. Four ambulances and the two golf-carts were fully staffed.

With the possibility of a mass-casualty event in mind, given the lack of space within the stadium perimeter, a fixed 


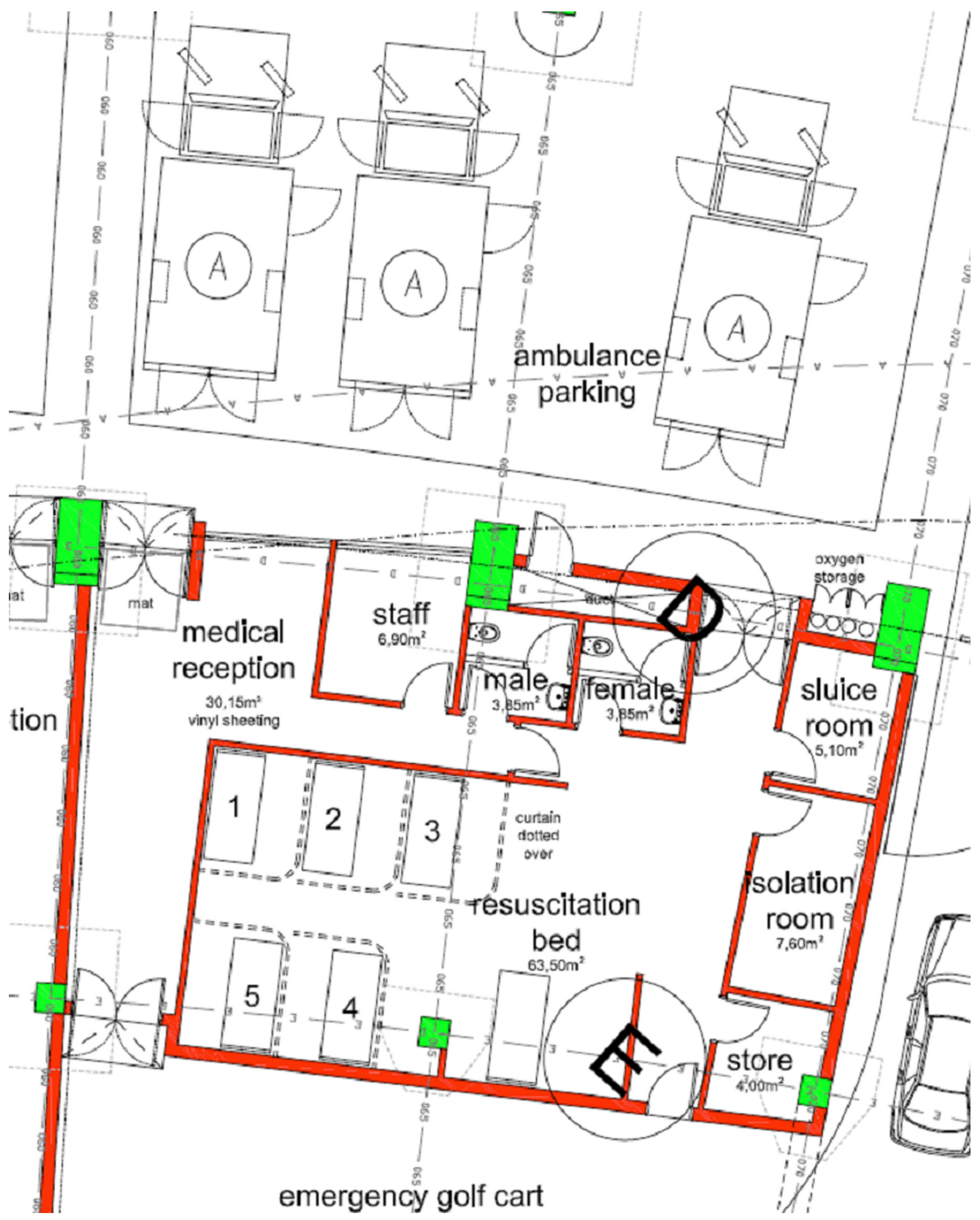

Figure I Plan of the Stadium Spectator Medical Center.

major incident Casualty Clearing Station was also set up at an adjacent venue in close proximity to a large stadium exit. This area was designed to manage any eventuality including any chemical, biological, radio-nuclear, or explosive event. It was designed to manage around 200 casualties at any one time. Over and above the staff inside the stadium, this area was provided with a separate staff, equipment, and vehicle allocation, held as a reserve force.

\section{The process}

About 12 months before the events commenced, there was intense planning involving the stadium and the requirements 
for the medical equipment and medications required. Eventually the decision was to equip the Spectator Medical Center and the Players' Medical Centers to manage major resuscitation cases, while the other areas would remain intermediate life support capable, with advanced life support practitioners available at all times. ${ }^{10}$

About 3 months before the stadium was handed to FIFA, the EMRS and other role-players held "trial runs" during smaller local football matches and other large events held at the stadium to test both the ability of the stadium to handle the events and the service's ability to manage those attending the event. These events ensured that minor teething troubles, as experienced at the Casualty Clearing Station site (which was specific to the FIFA event) on the night of the first match, did not occur at the stadium on handover to FIFA.

\section{Clinical care and patient profiles during the FIFA events}

The medical centers at the stadium that are reviewed here treated only the spectators, the media, and stadium support staff. While the VIP area was provided with medical cover, most VIPs had their own medical support, and the FIFA players and officials had team medical staff or Local Organizing Committee medical officers to provide needed medical care. Data were collected on a proforma case sheet and recorded on a computerized daily summary for forward transmission to the National Department of Health.

Three hundred sixteen patients were treated by the stadium medical personnel. The average patient age was 31.6 years (range 5-75 years), with males constituting $60 \%$ of the patient load. Only 10 patients under the age of 12 were treated during the seven matches. The spectrum of patients included 231 (73\%) spectators, 71 (23\%) support staff, and 13 members of either the police or media contingent. No VIP required treatment.

The patient profile reveals that in accordance with much of the literature on mass gatherings, the majority of the 316 cases were minor ailments that could be managed with simple means of assessment, treatment, and discharge. Approximately 476,000 spectators and support staff were in the stadium venue for the seven matches. Only 13 patients required transport to hospital out of a total of 316 patients treated over the course of seven matches. This constitutes a patient presentation rate (PPR) for spectators of $0.66 / 10,000$, while the transport to hospital rate (TTHR) was $4.1 \%$ of all patients treated at the seven matches, or $0.027 / 10,000$ spectators. Interestingly the majority of persons treated were locals, with only nine $(2.85 \%)$ foreign visitors treated at the Moses Mabhida Stadium.
The triage system used for coding severity of injury is detailed in Table 1 . The majority of patients were minor (278 Green codes, 88.2\%), while the small percentage of Yellow codes were coded as such mainly due to the need for wheel-chair or stretcher for transportation (35 Yellow codes, $11.2 \%)$. There were only two patients $(0.6 \%)$ classified as critical (Red codes), and one of these cases subsequently demised in hospital due to massive intracerebral hemorrhage. The only death on site (Blue code) was a pedestrian walking to the stadium on the very first match who collapsed inside the security zone, but about $2 \mathrm{~km}$ from the stadium medical points (see stadium site plan Figure 2). By the time the golf-cart team was able to penetrate the advancing crowd and reach the patient, he was already dead due to a massive myocardial infarct. Cardiopulmonary resuscitation had been commenced by a passing medical doctor and continued until the golf cart arrived, but was to no avail. Contributing factors may have been that this was a patient who was known to have ischemic heart disease and he was required to walk $2 \mathrm{~km}$ from the drop-off zone to the security gate.

The spectrum of medical and traumatic pathology is tabulated in Table 2. The most common complaints were headaches, abdominal (including gynecological) complaints, soft tissue injury, eyes, ears/nose/throat (ENT), and minor lacerations. These together constituted 257 of the 316 patients treated $(81.3 \%)$. Interestingly, despite the liberal consumption of alcohol at the venue, there were only three cases of alcohol poisoning reported. The incidence of acute allergy or asthma can possibly be explained by the fact that the majority of the matches were played during the early evening or at night and that the season was winter-time. The relatively high incidence of cardiovascular and diabetic cases can be explained by the fact that the walking distance from the bus-drop zones and parking areas to the stadium averaged around $4-5 \mathrm{~km}$, requiring more than the usual exercise for these "at risk" patients.

\section{Discussion}

The role of the Department of Health in the provision of services was guided by the government's guarantees to FIFA. The Minister of Health committed to FIFA that the infrastructure

Table I Triage coding $(n=316)$

\begin{tabular}{ll}
\hline Code & $\begin{array}{l}\text { Number of } \\
\text { patients }\end{array}$ \\
\hline Red - critical injury and impaired vital signs & 2 \\
Yellow - stable, but requires stretcher transportation & 35 \\
Green - walking wounded or stable ambulant & 278 \\
medical problem & \\
Blue - dead & $\mathrm{I}$ \\
\hline
\end{tabular}




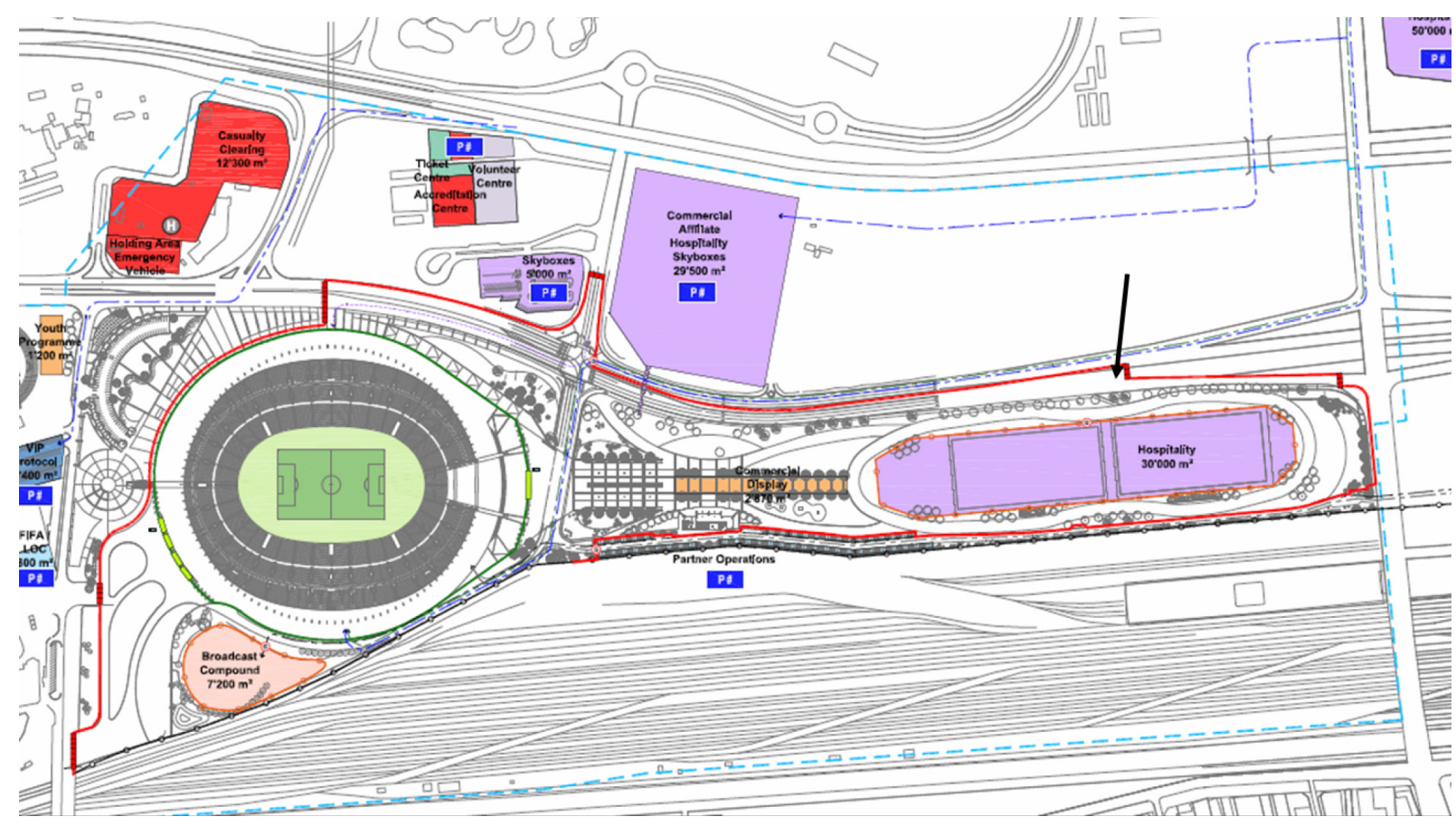

Figure 2 Stadium site plan. Red line, security perimeter; blue line, no-drive zone; arrow, site of fatality.

of the South African National Health System, specifically a comprehensive medical service (including 24-hour emergency medical treatment) and disaster management plan would be put at the disposal of the 2010 FIFA World Cup ${ }^{\mathrm{TM}}$ in the cities where the games will be played.

It must be stated, however, that in as much as the FIFA had specific requirements of what medical services were required and where to locate them, there were no FIFA specific guidelines and standards to determine the acceptable level of preparedness or to justify the specific resource allocation for rendering medical services or for the provision of major incident response capability. ${ }^{11}$

A large body of literature exists regarding mass-gathering medicine, and while much of the literature is of low-evidence quality, the publications detail a number of methods to determine staffing and equipment norms for such events. ${ }^{5-7}$

Table 2 Diagnosis: descending order of frequency $(n=316)$

\begin{tabular}{ll}
\hline Pathology & Number \\
\hline Headache & 82 \\
Abdominal complaints & 52 \\
Soft tissue injury & 50 \\
Eyes/ENT & 36 \\
Minor lacerations & 31 \\
Allergy/asthma & 17 \\
Other trauma (burns/fracture/blisters) & 17 \\
Cardiovascular or diabetic (including collapse) & 16 \\
Heat/cold-related pathology & 12 \\
Alcohol intoxication & 3 \\
\hline
\end{tabular}

Abbreviation: ENT, ear/nose/throat.
An extensive literature review ${ }^{5}$ was published by Milsten et al resulting in a call for a more scientific approach to the reporting of such mass-gathering events, including the use of defined data points, such as PPR usually in patients per ten thousand (PPTT), and TTHR. ${ }^{6}$

The broad public health aspects of mass gathering medicine were reviewed by a collaborative study group prior to planning for the current soccer event, and many of the concepts espoused by Milsten et al, ${ }^{5}$ Arbon, ${ }^{6}$ and Arbon et $\mathrm{al}^{7}$ as well as other public health issues, such as water and air purity, were addressed, including the need for mass casualty planning. ${ }^{4}$ No specifics, however, were provided in terms of norms for an event of this nature, as there were no published reports on which to base the recommendations specific to a Soccer World Cup event, since very little has been written regarding specific aspects of patient care at soccer stadiums in general, and nothing that examined specifically the medical care of spectators at a World Cup event was found in the English literature.

Most of the literature refers to specific stadium incidents, ${ }^{12-14}$ while three recent papers were found that examine the experiences of specific club venues during British football seasons. ${ }^{15-17}$ These papers are utilized as the basis for comparison of the patient care at Moses Mabhida stadium during the recent FIFA World Cup games.

When the English soccer literature is compared, PPRs average 0.42-3.1 PPTT, which is in keeping with the rate seen at the local stadium, where a rate of 0.66 was noted. TTHR 
was low (4.1\%), largely due to the presence of doctors on site who were able to treat and discharge patients who were stable after intervention. ${ }^{18,19}$ This compares favorably with the overall published rates between $9 \%$ and $20 \%$ for the English Football League literature. ${ }^{15-17}$ It is interesting to note that although the rate of hospital transports is lower than the British literature it is indeed in keeping with other events and other sporting codes, with rates between $4 \%$ and $20 \%{ }^{20-24}$

The average age (31.6 versus average 34 years) and gender mix (60\% male compared with 54\%-75\%) treated at the stadium are in keeping with the published literature. The majority of patients were of a minor or moderate severity of injury, or illness, in keeping with the published rates (88\%-99\%). ${ }^{6,15-24}$ This is despite most of the planning for such mass gatherings focusing on rapid access and treatment of the severely injured or ill. $^{6}$ Interestingly, we noted low rates of heat- or cold-related illness (3.2\%) compared with some of the previous reports, where rates around 10\%-12\% are reported, despite most of the matches occurring in the cool winter Durban evening. .,23,24 $^{2}$

There is, however, the likelihood that some of the cases of either asthma or cardiac complaints (mainly in older attendees) were also related to the cool climate combined with the need for a long walk of around $3 \mathrm{~km}$ from the parking and bus-drop areas to the stadium, due to the no-drive security exclusion zone, given that most of the games were played in late afternoon or evening during the Durban winter, despite there being a moderate winter climate (Table 3). Interestingly, all 12 cases of cold-related problems were recorded on the 22nd of June, during a match from 8:30 pm to 11:00 pm on a particularly cool evening. This is of particular relevance in light of the call for research to evaluate the effect of mass gatherings on vulnerable populations, such as the elderly, as well as to identify factors that could prevent pathology from occurring. ${ }^{6}$

Another interesting fact is the high incidence of headaches and ENT complaints noted among the medical complaints.

Table 3 Games at Moses Mabhida Stadium

\begin{tabular}{|c|c|c|c|c|}
\hline Match number & Time & Date & Team I & Team 2 \\
\hline I & $20: 30 \mathrm{~h}$ & June 13,2010 & Germany $^{\mathrm{a}}$ & Australia \\
\hline 2 & $16: 00 \mathrm{~h}$ & June 16,2010 & Spain & Switzerland ${ }^{a}$ \\
\hline 3 & $13: 30 \mathrm{~h}$ & June 19, & Netherlands ${ }^{\mathrm{a}}$ & Japan \\
\hline \multirow[t]{2}{*}{4} & $20: 30 \mathrm{~h}$ & June 22,2010 & Nigeria $^{a}$ & Korea \\
\hline & & & & Republic \\
\hline 5 & $16: 00 \mathrm{~h}$ & June 25,2010 & Portugal & Brazil \\
\hline 6 - Round of 16 & $16: 00 \mathrm{~h}$ & June 28,2010 & Netherlands ${ }^{a}$ & Slovakia \\
\hline 7 - Semi final & $20: 30 \mathrm{~h}$ & July 7,2010 & Spain $^{\mathrm{a}}$ & Germany \\
\hline
\end{tabular}

Note: ${ }^{a}$ Winning team: Portugal/Brazil draw.
This begs the question as to whether the noise levels generated by the use of the Vuvuzela trumpets have increased the incidence of noise-trauma, which was suggested by a recent publication in the local medical literature. ${ }^{25}$ This is, however, in common with the most recent British soccer literature, with the overall spread of pathology being remarkably similar to that seen at the Millwall FC stadium. ${ }^{16}$

The low rate of alcohol-related pathologies is in keeping with the more recent reports from the British soccer fraternity and may be related to the strong presence of police and security forces at the event. ${ }^{16,17}$ This is in sharp contrast to the report from Celtic FC where the abuse of alcohol was highlighted as an emerging problem. ${ }^{15}$

The majority of the health care providers were ambulance staff, trained with the focus on potential mass-casualty situations ${ }^{26}$ and who are not at liberty to prescribe certain medications; thus, having doctors and nurses on-site prevented the need for higher TTHRs. This is in contrast with recent publications. ${ }^{6}$ The lesson that was learned, however, is that there is a need for a wider selection of over-the-counter and prescription medications on-site for minor ailments to avoid having to give discharge scripts to certain patients. Finally, despite the systemic plans including the receiving hospitals and the provision of adequate resources for routine day-to-day emergency care, the hospitals were fairly quiet, in keeping with the published literature. ${ }^{5}$

\section{Conclusion and recommendations}

In conclusion, the experiences of the medical support services at the Moses Mabhida stadium show that the majority of spectators and support staff that seek medical attention do so for minor complaints, which can be easily assessed and managed, with most able to discharge home after the event. The low TTHR is most likely impacted by this factor.

The spectrum of pathology is similar to published series with the exception of the low rate of alcohol intoxication compared with other centers and the high headache rate possibly due to the noise levels. A wider selection of onsite medication for these minor ailments would reduce the need for discharge scripts. This information may assist those planning similar care for future FIFA World Cup ${ }^{\mathrm{TM}}$ tournaments.

\section{Acknowledgments}

The authors wish to thank the staff who worked each match day at the site, from all the emergency, medical, and military health services, especially those who worked as unpaid volunteers. 


\section{Disclosure}

No conflicts of interest are noted and no financial sponsorship was received in the writing of this paper.

\section{References}

1. Ligthelm TJ. Gevlous met die Pous [in Afrikaans]. Trauma Emerg Med. 1992;9(2):573-577.

2. Tshabalala-Msimang M, Pillay Y. Preparing the Health Sector for the 2010 Soccer World Cup. S Afr Med J. 2007; 97:40.

3. Smith W. Mass-gatherings medicine: South Africa - alive with possibility. Emergency Services SA/Occupational Risk. 2009;1(4):9-20.

4. Yancey A, Fuhri PD, Pillay Y, Greenwald I. World Cup 2010 planning: an integration of public health and medical systems. Public Health 2008;122:1020-1029.

5. Milsten AM, Maguire BJ, Bissell RA, Seaman KG. Mass gathering medical care: a review of the literature. Prehosp Disaster Med. 2002;17: 151-162.

6. Arbon P. Mass-gathering medicine: a review of the evidence future directions for research. Prehosp Disaster Med. 2007;22:131-135.

7. Arbon P, Franklin HG, Bridgewater MB, Smith C. Mass gathering medicine: a predictive model for patient presentation and transport rates. Prehosp Disaster Med. 2001;16:150-158.

8. Emergency Medicine Society of South Africa: Practice Guideline EM009: Mass Gathering Medical Resource Model. 2009 Oct. Available from: www.emssa.org.za. Accessed Jun 282010.

9. SANS 10366. Health and Safety at Events - Requirements. Pretoria, South Africa: South African Bureau of Standards Bulletin; 2009.

10. Department of Health KZN. Medical Facilities Planning 2010. Document for Moses Mabhida Stadium; 2008.

11. Dvorak J, Grimm K. Medical Services at FIFA WC 2010. Zurich, Switzerland: FIFA; 2007.

12. Bradford City Fire Disaster Fifty Six People. Available from: http:// bradfordcityfiredessaster-fiftysixpeople.gonetoosoon.org/memorial/ Accessed Jun 242010.

13. Bowley DM, Rein P, Hendrik JS, Boffard K. The Ellis Park Stadium tragedy. Eur J Trauma. 2003;1:51-55.
14. Joubert DA. Sport disaster Oppenheimer: 1991. Trauma Emerg Med (SA). 1992;9(2):570-572.

15. Crawford M, Donnelly J, Gordon J, et al. An analysis of consultations with the crowd doctors at Glasgow Celtic football club, season 1999-2000. Br J Sports Med. 2001;35:245-250.

16. Leary A, Greenwood P, Hedley B, Agnew J, Thompson D, Punshon G. An analysis of use of crowd medical services at an English football league club. Int Emerg Nurs. 2008;16:193-199.

17. Bhangu A, Agar C, Pickard L, Leary A. The Villa Park experience: crowd consultations at an English Premiership football stadium, season 2007-2008. Emerg Med J. 2010;27:424-429.

18. Martin-Gill C, Brady WJ, Barlotta K, et al. Hospital based healthcare provider (nurse and physician) integration into an emergency medical services managed mass gathering event. Am J Emerg Med. 2007;25: $15-22$.

19. Grange JT, Bauman JW, Vaezazizi R. On site physicians reduce ambulance transports at mass gatherings. Prehosp Emerg Care. 2003; $7: 322-326$.

20. Wetterhall SF, Coulombier DM, Herndon JM, et al. Medical care delivery at the 1996 Olympic Games. JAMA. 1998;279:1463-1468.

21. Allen TL, Jolley SJ, Cooley VJ, et al. The epidemiology of illness and injury at the Alpine venues during the Salt Lake City 2002 Winter Olympic Games. J Emerg Med. 2006;30:197-202.

22. Grissom CK, Finnoff JT, Murdock DC, Culberson JT. Nordic venue medical services during the 2002 Winter Olympics. J Emerg Med. 2006; 30:203-210.

23. Baker WM, Simone BM, Niemann JT, Daly A. Special event medical care: the 1984 Los Angeles Summer Olympics experience. Ann Emerg Med. 1986;15:185-190.

24. Thompson JM, Savoia G, Powell G, Challis EB, Law P. Level of medical care required for mass gatherings: the XV Winter Olympic Games in Calgary, Canada. Ann Emerg Med. 1991;20:385-390.

25. Swanepoel D, Hall JW III, Koekemoer D. Vuvuzela - good for your team, bad for your ears. S Afr Med J. 2010;100:99-100.

26. Hardcastle T. Emergency preparation for FIFA 2010. A legacy in the making. Emergency Services SA/Occupational Risk. 2010;1(5): $14-15$.
Open Access Emergency Medicine

\section{Publish your work in this journal}

Open Access Emergency Medicine is an international, peer-reviewed, open access journal publishing original research, reports, editorials, reviews and commentaries on all aspects of emergency medicine. The manuscript management system is completely online and includes a very quick and fair peer-review system, which is all easy to use.

\section{Dovepress}

Visit http://www.dovepress.com/testimonials.php to read real quotes from published authors. 